\title{
Changing and Transforming a Story in the Framework of an Automatic Narrative Generation Game
}

\author{
Jumpei Ono \\ Graduate School of Software Informatics, Iwate Prefectural University \\ Takizawa, Iwate, 020-0693, Japan \\ Takashi Ogata \\ Department of Software Informatics, Iwate Prefectural University \\ Takizawa, Iwate, 020-0693, Japan \\ E-mail: g236m001@s.iwate-pu.ac.jp,t-ogata@iwate-pu.ac.jp
}

\begin{abstract}
We propose the concept of a game system that includes an automatic story-generation function based on a table-top role playing game (TRPG). In this idea, stories are generated or transformed based on communication between a "game master (GM)," who controls the story generation, and "players (PLs)," who change and transform the content of a story proposed by a GM. This paper focuses on the mechanism for changing and transforming a story proposed by the GM. In particular, the proposed mechanism has various techniques ranging from macro-level techniques, which are related to the entire structure of a story, to micro-level techniques, which are related to the partial structures of a story. For instance, when the GM is a real human, these techniques in the PLs, who are computer agents, can produce changed and transformed stories that were not originally conceptualized by the GM.
\end{abstract}

Keywords: Automatic narrative generation game (ANGG), Integrated narrative generation system (INGS), Tabletop role playing game, Story generation, Discourse.

\section{Introduction}

In this study, we propose a mechanism for a computer game system using an automatic story generation function based on a tabletop-top role playing game (TRPG). Here, stories are generated and transformed via a communication loop between a "game master (GM)," who generates the first framework of a story and controls or manages the subsequent story generation process, and "players (PLs)," who modify and transform the story that was first generated by the GM. This paper focuses on the problem associated with the mechanism for changing and transforming a story proposed by the GM. Although this mechanism is currently implemented using a simple method, in this paper, we discuss various techniques that range from macro-level techniques, which are related to the overall structure of a story, to micro-level techniques that are related to the partial structures of a story. We aim to design and implement the future expansion of the system.

We refer to the game system, including the automatic narrative generation mechanism, as an "automatic narrative generation game (ANGG)." In this system architecture, each GM and PL can be either a computer agent or a human. When the GM is a real human, a variety of narrative techniques employed by PLs who are computer agents enable the production of changed and transformed stories that the GM did not imagine originally. When both the GM and PLs are computer agents, they can use the narrative generation mechanisms in the integrated narrative generation system (INGS) described in the following section to 
generate a story framework and transform the story framework into the expanded stories. Thus, the ANGG is regarded as a kind of narrative generation system through the corporative relationships between the GM and the PLs.

As Ogata ${ }^{1}$ presented a detailed description, Fig. 1 shows an overview of the INGS architecture. From a macro perspective, the INGS is divided into three generation processes or mechanisms, namely a story, discourse, and representation. Ogata ${ }^{1}$ presents a detailed list of all of the modules in the current INGS. Generally, the story generation mechanism generates a story structure that contains a sequence of events. Then, the discourse mechanism transforms the story structure generated by the story generation mechanism into a discourse structure that contains edited by the narrative logic, namely the structure of a narrative to be narrated. Further, the representation mechanism transforms the narrative structure into a surface narration using natural language, music, and a picture image.

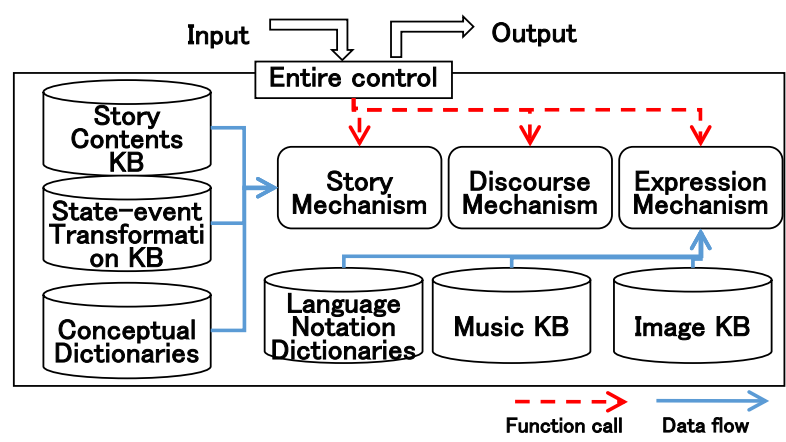

Fig. 1. The INGS Architecture.

The GM and PLs in the ANGG respectively correspond to the story generation mechanism and the discourse mechanism in the INGS. From the perspective of the GM, a story that the GM generated is changed and transformed by the PLs into a more interesting story. In this case, the story is called a discourse in the INGS. The GM also controls and manages the transformation and change process to make an expanded discourse or to indicate the need to make an alternative discourse. On the other hand, the PLs collectively change and transform the story under the control and management of the GM to expand it through the communication cycle between the GM and the PLs.

Ono and Ogata ${ }^{2-5}$ presented the architecture of an ANGG system. Ono and Ogata $^{2}$ located a mechanism that set a story world in the ANGG, and Ono and Ogata ${ }^{6}$ proposed a mechanism for expanding a scene in the framework story generated by the GM in order to make a longer story. In this paper, we focus on the aspect of the story generation and discourse generation techniques with the aim of extending narrative generation techniques in future ANGGs. These correspond to the techniques that are used to arrange the story-generation mechanism and discourse generation mechanism in the INGS, and the many parts can be used in both the ANGG and INGS. However, important differences are that the PLs in the ANGG generate and transform a prepared story framework through the collective and corporative process, and narrative generation is generally conducted considering the interaction and the GM and the PLs.

\section{ANGG Overview and Story and Narrative Generation}

Fig. 2 shows an overview of the story generation process in the ANGG. From the perspective of story or narrative generation, the ANGG comprises two types of generation mechanisms by the GM and PLs. In particular, in the first step in the communication cycle, the GM generates the framework of a story that is to be incrementally extended into an extended story. Then, the PLs receive the framework story to generate a partial discourse to be inserted or added to the story. Finally, in the PL mechanism, several PLs collectively generate a new partial narrative. Currently, this requires a method that inserts an event between the two events in the framework story until the decided connection condition is satisfied for the next event in the framework story. The framework story refers to a story in the INGS that is generated using the story generation mechanism. On the other hand, the transformed or changed narrative corresponds to a discourse in the INGS that is transformed according to the discourse mechanism. However, in practice, the PLs can also use techniques in the story generation mechanism. In addition, the ANGG uses the "world setting," which means both a set of elements for stories and a set of constraint information that is used to define the range of possibilities.

A variety of collective or corporative narrative generation or transformation methods can be considered in order to extend the ANGG. Based on the current method, all PLs propose candidates for expansions of an original story or discourse, and only one is selected to 


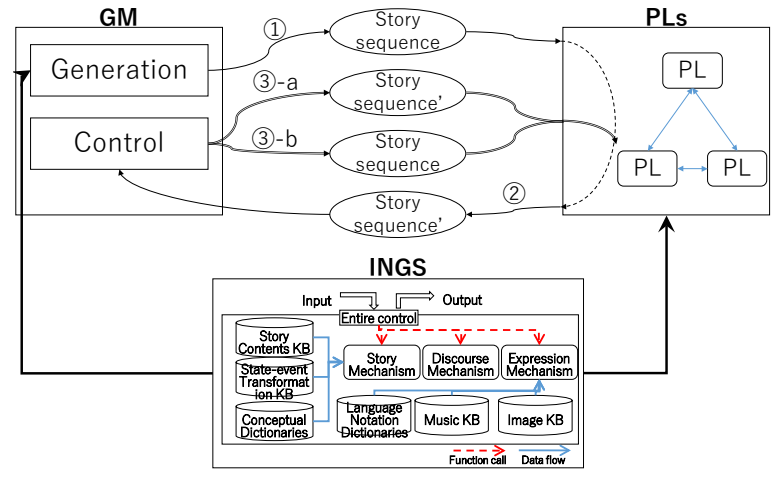

Fig. 2. A story generation process in ANGG.

be given to the GM. Discourses that are made by all PLs can also be combined into the final proposed discourse. In addition, various types of discourses may be proposed to the GM, and include methods that embody or extend a part of the framework story generated by the GM, and that transform the flow of the entire story. Further, each PL plays a character in a story world, and the narrative generation by the PLs is executed based on the characters' perspectives. A function in the communication process among PLs determines which PL is the main character in the story world. Thus, goalplanning story generation is one of the basic narrativegeneration methods that are used. We discuss these narrative generation problems faced by PLs in another paper.

After the PLs first propose a discourse that transforms and changes the framework story generated by the GM, the GM evaluates whether to directly adopt the proposition. If the proposed discourse (or the fragmental extension) is adopted, the GM creates a new story that reflects the discourse proposed by the PLs. In contrast, if the proposed discourse or the fragmental extension is not adopted, the GM instructs the PLs to repeat the narrative generation for the framework story until the GM decides to adopt it. After the second process, this cycle, which is referred to as narrative transformation by the PLs and narrative evaluation by the GM, continues until a complete narrative is eventually generated. As stated above, in the ANGG, the GM has roles that include generating the first story framework and controlling the post-game progression. On the other hand, the main role of the PLs is to transform and change the framework story generated by the GM in an attempt to propose partial stories.

In the above system's architecture, the ANGG can use story and discourse generation techniques in the
INGS that we have presented. The main types that are relevant to the PLs are described in section 3. The ANGG can also refer to previous research to elaborately design the interactive mechanisms between the GM and the PLs as well as between the PLs. In section 4, we introduce the related previous research.

\section{Methods for Story Generation and Transformation}

In this section, we introduce various mechanisms that transform a story into various discourse structures.

\subsection{Story and Discourse in a Narrative}

First, the "narrative discourse mechanism" in the INGS architecture shown in Fig. 1 provides the most fundamental narrative mechanism that is used for changing and transforming a story generated by the story generation mechanism. Fig. 3 shows an example where a story structure is transformed into a discourse structure; a relationship specified to discourse, "presentbackward" is added to the story structure. The structures for both the story and the discourse have similar tree forms. Each leaf node in a story tree corresponds to an event described with conceptual representation, which is further described by a case structure that consists of one verb concept and eight types of cases, such as "agent" and "object." Each internal node in the tree is equivalent to a "relationship," such as "cause-effect" and "serial," combined with the child nodes. The ANGG can use this type of method as a narrative discourse technique to change and transform the framework of a story that is generated by the GM.

We began this study by modifying the theory's context proposed by Genette ${ }^{7}$, who is a French narratologist, and we used a computational viewpoint to create a technological method for the design or formalization of the narrative discourse generation

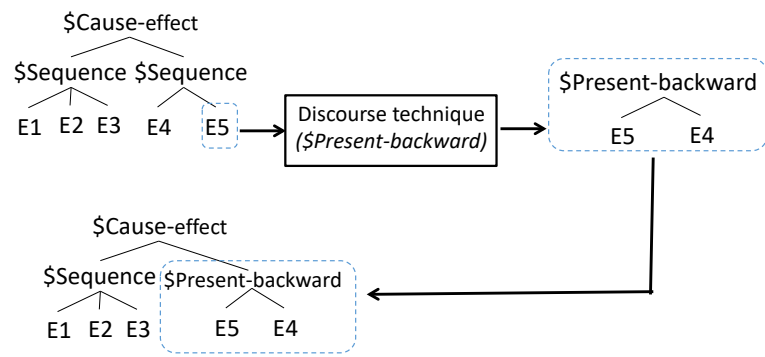

Fig. 3. Transformation from story structure to discourse structure. 
mechanism. This allows each of the classified techniques applied by Genette to be used as a rule for associating an input story structure with a transformed output discourse structure. However, the aim of studying the narrative discourse mechanism is not only to apply the narratology proposed by Genette. It is also expanded to other narrative discourse techniques. We designed a more comprehensive narrative discourse system by integrating various narrative discourse types, including the following techniques, into a systematic list.

\subsection{Defamiliarization Techniques}

Zhang, Ono and Ogata ${ }^{8}$ classified the methods of the relationships between a product and the story by performing an analysis of over 5000 television commercial films to define its result as "rhetorical techniques of introducing a product into a single event." The previous study classified the rhetorical techniques into either regular rhetoric or standard rhetoric during the of production, distribution, and utilization processes of a product. On the other hand, they defined irregular rhetoric based on "defamiliarization" ("ostranenie" in Russian) or a deviation from the regular rhetoric. Defamiliarization rhetoric indicates techniques that transform the whole of a part or an element included in a story into an extraordinary object that is different from people's ordinary feeling to strengthen the impression of the element itself.

Table 1 shows 12 defined types of rhetoric. A "rhetoric" refers to a technique that is used to introduce a product in an impressive way by employing an advertising scenario, while a "single event" refers to a unit that contains several elements such as a person, object, location, and time, which are associated with a single action in the flow of the story. In the table, rhetorical techniques from R1 to R3 generate scenes of standard or ordinary use methods of products. On the other hand, the rhetorical techniques from R4 to R12 generate defamiliarization scenes by applying the extraordinary rhetoric. The irregular techniques partially use the "changing constraint" method, which changes usable concepts in the conceptual dictionaries in the INGS (Fig. 1) to adjust the semantic range of concepts to enable them to be set into an event.

\subsection{Film Rhetoric by Kanai}

Story cutting techniques proposed by Kanai ${ }^{9}$ aim to cut a story's consistency in order to strengthen only a
Table 1. Classification of TV-CF rhetorical techniques.

\begin{tabular}{|c|c|c|}
\hline & Object & Type of Rhetoric \\
\hline 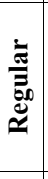 & & $\begin{array}{l}\text { R1 original method of manufacturing: the original } \\
\text { way that the product is manufactured. } \\
\mathbf{R 2} \text { original method of purchasing: the original way } \\
\text { that the product is purchased. } \\
\mathbf{R 3} \text { core rhetoric: the way that the product is originally } \\
\text { used. }\end{array}$ \\
\hline \multirow{8}{*}{ 章 } & Action & $\begin{array}{l}\text { R4 defamiliarization: the defamiliarized way that the } \\
\text { product is used. } \\
\text { R5 none use of rhetoric: no deviation, just "hold." }\end{array}$ \\
\hline & & $\begin{array}{l}\text { R6 character as a narrator: rather than being involved } \\
\text { in the story, the character sends a message to viewers } \\
\text { directly. }\end{array}$ \\
\hline & Person & $\begin{array}{l}\text { R7 state defamiliarization of the character: changing } \\
\text { all or part of the character, or the character daily uses the } \\
\text { product in an impossible way. }\end{array}$ \\
\hline & & $\begin{array}{l}\text { R8 action defamiliarization of the character: the } \\
\text { character does not perform the original action, but } \\
\text { performs defamiliarity. }\end{array}$ \\
\hline & & $\begin{array}{l}\text { R9 state defamiliarization of the product: changing all } \\
\text { or part of the product. }\end{array}$ \\
\hline & Things & $\begin{array}{l}\text { R10 state defamiliarization of related things of the } \\
\text { product: changing all or part of the related things of the } \\
\text { product. }\end{array}$ \\
\hline & & $\begin{array}{l}\text { R11 product subjectification: instead of being used } \\
\text { by a character, here, it emphasizes that the product } \\
\text { exists independently. }\end{array}$ \\
\hline & Location & $\begin{array}{l}\text { R12 background defamiliarization: all or part of the } \\
\text { background is changed into } \\
\text { something entirely decorative, which is impossible to do } \\
\text { daily. }\end{array}$ \\
\hline
\end{tabular}

specific element in the story. This is done by lacking a temporal sequence and a character's consistency in continuous scenes in a film. For example, in a battle scene in a war film, the use of cutting techniques by inserting a silent scene and a scene where the temporal continuity is ambiguous contribute to strengthening the impression of scenes that are independent of a story's semantic progression.

Kanai and Kodama $^{9}$ proposed a high-level classification of cutting techniques that (1) emphasizes editing itself by making a differentiation or discontinuity in the elements among continuous shots, which includes destroying the continuity of events, (2) emphasizes the image itself by irrationalizing or destroying the relationships between an event and the image, which includes repetitive filming of the same object, and (3) emphasizes the sound itself by irrationalizing the relationships between sound and the image, which includes lacking the relationships between speech and the visual image.

Furthermore, considering the above large classification, Kanai ${ }^{9}$ presented the following sixteen types of cutting technique. In the description, "dialectic" refers to a unified whole. On the other hand, in "cutting," it appears as itself, and the temporal order cannot be recognized by the user. In "metric," the continuity time of all shots is the same. On the contrary, the continuity 
time in each shot varies according to the action's time. "Tonal" and "overtonal" do not initially determine the continuity time.

- (1) Dialectic metric, (2) Dialectic rhythmic, (3) Dialectic tonal, and (4) Dialectic overtonal: (1), (2), and (3), respectively have different lengths of shots, and (4) mixes a shot with different sounds into a sequence of shots.

- (5) Temporal sequence cutting metric, (6) Temporal sequence cutting rhythmic, (7) Temporal sequence cutting tonal, and (8) Temporal sequence cutting overtonal: These prevent a receiver from representing the temporal sequence of events in a cognitive manner.

- (9) Characters cutting metric, (10) Characters cutting rhythmic, (11) Characters cutting tonal, and (12) Characters cutting overtonal: These cut the continuity of a character, and there are no shots where the same character continuously appears.

- (13) Temporal sequence/characters cutting metric, (14) Temporal sequence/characters rhythmic, (15) Temporal sequence/characters tonal, and (16) Temporal sequence/characters overtonal: These prevent a receiver from representing the temporal sequence of events in a cognitive manner. In addition, there are no shots where the same character continuously appears.

\section{Generation by Narrative Communication}

Akimoto and Ogata ${ }^{10,11}$ presented a computational narrative model in which literary works are continuously changing owing to the interaction between an author or narrator and a reader or narrator (these are computer agents within the system) for a narrative discourse control mechanism in the INGS. In the system modeling, Jauss' reception theory ${ }^{12}$ is simply interpreted as a mechanism to limit the discourse process through the interaction between a narrator mechanism with generative parameters and a narratee mechanism with expectation parameters. In this study, we mixed this Jauss-based mechanism with the Genette-based mechanism mentioned in section 3.1 to form a model and system that control the deviation of a narrative discourse mechanism based on the interaction between a narrator mechanism and a narratee mechanism within a narrative.

This system is a model of Jauss' reception theory, where literary works are repeatedly produced according to a reader's expectations and the corresponding responses from an author; the interaction can continuously or historically change a literary work. In particular, texts of narrative discourses are repeatedly produced through a process according to parameters for a reader (or narratee) as the expectation, and using the same parameters for an author (or narrator) as the generative goals. These parameters are the same as those in the Genette-based mechanism.

The cycle continues according to the interaction between a narrator and narratee. The narrator mechanism has a set of rules for controlling the application of discourse techniques based on the generative parameters to transform a discourse structure. We performed the direct transformation of a discourse structure using techniques defined by Genette's theory. The narratee mechanism evaluates the results by comparing the narratee's expectation parameters with the narrator's generated parameters. In the next cycle, the narrator applies corrections according to the narratee's evaluation in order to achieve reader satisfaction. However, the process eventually reaches a point where the narratee becomes tired or when his/her satisfaction begins to fall. When this happens, "deviation" occurs and the narrator abandons some of the old generative parameters and moves to a new cycle of discourse grounded on the newly found strategy. The narratee's expectations change according to the reconstruction.

Fig. 4 is a detailed process flow of the narrative discourse control based on the interaction between the narrator and narratee mechanisms. As seen in (1), the system selects the corresponding techniques according to the parameter values. In (2), the Genette-based techniques fulfill the functions in the context of the Jauss-based control. In (3), a higher satisfaction can be obtained when a more strongly desired parameter is satisfied. The narratee indicates one parameter with the lowest satisfaction. In (4), the narratee rewrites an expectation parameter using two different procedures. The first rewrites the sufficiency number and degree of desire. The former is increased each time the narratee receives the sufficed discourse. Finally, (5) includes "deviation" from the expectation.

\section{Conclusions}

In this paper, after we presented an overview of the ANGG system that we developed, we considered story generation and discourse techniques to utilize the GM 


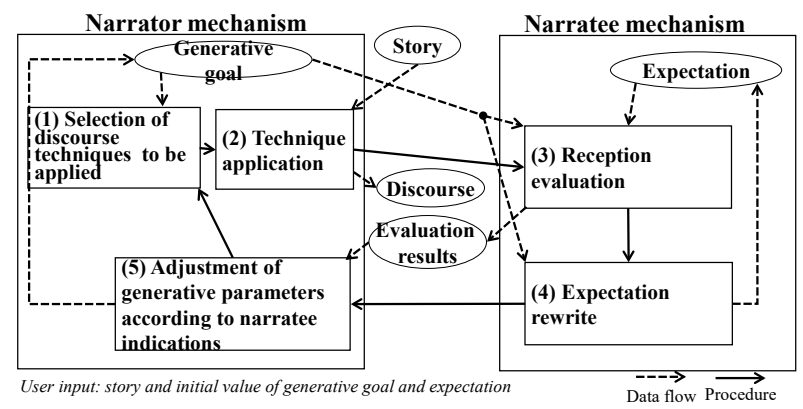

Fig. 4. Interaction between narrator and narratee.

and PLs used in the ANGG in the future. These techniques are provided by the story-generation mechanism and the discourse mechanism in the INGS. Therefore, although there is common narrative knowledge to be used in both the INGS and the ANGG, an important difference between the two systems is that narrative generation by the ANGG is performed considering the interaction between the GM and the PLs and the collective method among PLs. Table 2 shows a comprehensive list of narrative techniques for the GM and the PLs including the techniques described in this paper.

Table 2. Classification of narrative techniques.

\begin{tabular}{|l|}
\hline Macro level techniques \\
- Story-generation techniques \\
- Story grammar techniques \\
- Story-discourse transformation techniques [Section 3.1] \\
Medial level techniques \\
- Goal-planning techniques \\
Micro level techniques \\
- Event transformation techniques \\
- Rhetorical techniques [section 3.2] \\
- Cutting techniques [section 3.3] \\
\hline
\end{tabular}

In the future, we plan to extend the design of an integrated mechanism of the ANGG to incorporate various narrative techniques, including those proposed in this paper, interactive processing between the GM and the PLs, and collective processing among the PLs into a system architecture that enables changeable and diverse narrative generation.

\section{Acknowledgements}

This work is supported by the JSPS KAKENHI Grant Number 26330258 and the Support Center for Advanced Telecommunications Technologies Research Grant (2015-2017).

\section{References}

1. T. Ogata, Computational and Cognitive Approaches to Narratology from the Perspective of Narrative Generation, in Ogata, T. \& Akimoto, T. (eds), Computational and Cognitive Approaches to Narratology (IGI Global, Pennsylvania, 2016) 1-74.

2. J. Ono and T. Ogata, Architecture of a narrative generation system based on a TRPG model: the use of an integrated narrative generation system for knowledge acquisition (preliminary version), Bulletin of Netw., Comput., Syst., and Softw. 5(1) (2016) 40-48.

3. J. Ono and T. Ogata, A design plan of a game system including an automatic narrative generation mechanism: the entire structure and the world settings, J. Robotics, Networking and Artificial Life 2(4) (2016) 243-246.

4. J. Ono and T. Ogata, Towards a narrative generation system based on a TRPG model: the use of an integrated narrative generation system for an application system, in Proc. 21nd Int. Symp. on Artificial Life and Robotics (2016).

5. J. Ono and T. Ogata, Architecture of a narrative generation system based on a TRPG model: the use of an integrated narrative generation system, in Proc. 4th IIAE Int. Conf. on Industrial Application Engineering 2016 (2016) 138-145.

6. J. Ono and T. Ogata, Implementation of a Scene Expansion Mechanism using an Event sequence: As a Mechanism in an Automatic Narrative Generation Game, Proc. 3rd Int. Conf. on Knowledge Engineering (2016). (In printing).

7. G. Genette, Narrative discourse: An essay in method, trans. J. E. Lewin (Cornell University Press, New York, 1972).

8. Y. Zhang, J. Ono and T. Ogata, Single Event and Scenario Generation based on Advertising Rhetorical Techniques using the Conceptual Dictionary in Narrative Generation System, The 4th IEEE Int. Conf. on Digital Game and Intelligent Toy Enhanced Learning (2012) 162-164.

9. A. Kanai and K. Kodama, Film edit design: Story and irrational cutting, Cognitive Studies 17(3) (2010) 444458.

10. T. Akimoto and T. Ogata, A narratological approach for narrative discourse: Implementation and evaluation of the system based on Genette and Jauss, in Proc. of the $34^{\text {th }}$ annual conf. of the Cognitive Science society (2012) 1272-1277.

11. T. Akimoto and T. Ogata, An information design of narratology: The use of three literary theories in a narrative generation system, Int. J. Visual Design 7(3) (2014) 31-61.

12. H. R. Jauss, Literaturgeschichte als provokation, (Suhrkamp Verlag, Frankfurt am Main, 1970). 